\title{
The Neurobiological Mechanisms of Gamma-Hydroxybutyrate Dependence and Withdrawal and Their Clinical Relevance: A Review
}

\author{
Rama M. Kamal ${ }^{a, b}$ Martijn S. van Noorden ${ }^{c}$ Ernst Franzek ${ }^{b}$ \\ Boukje A.G. Dijkstra ${ }^{\text {a }}$ Anton J.M. Loonen ${ }^{d}$ Cornelius A.J. De Jong ${ }^{\text {a }}$

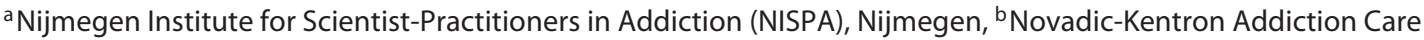 \\ Network, Vught, ' CLeiden University Medical Centre, Leiden, and ' Department of Pharmacy, University of Groningen, \\ Groningen, The Netherlands
}

\section{Key Words}

$\mathrm{Y}$-Hydroxybutyrate $\cdot$ Neurobiology - Dependence .

Withdrawal · Detoxification $\cdot$ Review

\begin{abstract}
Objective: $\gamma$-Hydroxybutyrate (GHB) has gained popularity as a drug of abuse. In the Netherlands the number of patients in treatment for GHB dependence has increased sharply. Clinical presentation of GHB withdrawal can be life threatening. We aim, through this overview, to explore the neurobiological pathways causing GHB dependency and withdrawal, and their implications for treatment choices. Methods: In this work we review the literature discussing the findings from animal models to clinical studies focused on the neurobiological pathways of endogenous but mainly exogenous GHB. Results: Chronic abuse of GHB exerts multifarious neurotransmitter and neuromodulator effects on $\gamma$-aminobutyric acid (GABA), glutamate, dopamine, serotonin, norepinephrine and cholinergic systems. Moreover, important effects on neurosteroidogenesis and oxytocin release are wielded. GHB acts mainly via a bidirectional effect on $G_{A B A}$ receptors $\left(G A B A_{B} R\right.$; subunits $G A B A_{B 1}$ and $\left.G A B A_{B 2}\right)$, depending on the subunit of the GIRK (G-protein-dependent ion inwardly
\end{abstract}

rectifying potassium) channel involved, and an indirect effect of the cortical and limbic inputs outside the nucleus accumbens. GHB also activates a specific GHB receptor and $\beta_{1^{-}}$ subunits of $a_{4}-G A B A_{A} R$. Reversing this complex interaction of neurobiological mechanisms by the abrupt cessation of GHB use results in a withdrawal syndrome with a diversity of symptoms of different intensity, depending on the pattern of GHB abuse. Conclusion: The GHB withdrawal symptoms cannot be related to a single mechanism or neurological pathway, which implies that different medication combinations are needed for treatment. A single drug class, such as benzodiazepines, gabapentin or antipsychotics, is unlikely to be sufficient to avoid life-threatening complications. Detoxification by means of titration and tapering of pharmaceutical GHB can be considered as a promising treatment that could make polypharmacy redundant.

(c) 2016 S. Karger AG, Basel

\section{Introduction}

$\gamma$-Hydroxybutyrate (GHB) is a short-chain fatty acid that occurs naturally in the human brain and acts as a neurotransmitter and neuromodulator [1]. GHB was de-

\section{KARGER}

E-Mail karger@karger.com

www.karger.com/nps
(C) 2016 S. Karger AG, Basel

0302-282X/16/0732-0065\$39.50/0
Rama M. Kamal, MD

Nijmegen Institute for Scientist-Practitioners in Addiction

Hogedwarsstraat 3, PO Box 243

NL-5260 AE Vught (The Netherlands)

E-Mail rama.kamal@novadic-kentron.nl 
veloped in the 1960s as an anaesthetic agent [2], but its use in anaesthesia remained limited due to inadequate analgesia, the emergence of delirium and its proconvulsive effect [3]. As a therapeutic drug $\left(\mathrm{Xyrem}^{\circledR}\right.$; sodium oxybate), GHB is currently used worldwide in the treatment of narcolepsy with attacks of cataplexy [4]. It is also approved in Austria and Italy to treat alcohol dependence and withdrawal (Alcover ${ }^{\circledR}$ ) [5], and it is used off-label for opiate withdrawal. In recent decades, GHB has gained popularity as a recreational drug and a drug of abuse in Europe and the Netherlands [6, 7]. However, GHB use seems to be on the low side. National estimates (for countries within Europe) of the prevalence of GHB use in both adult and school populations where GHB use exists remain low $(1-1.4 \%)[8,9]$. GHB use was reported as $2 \%$ among UK regular clubbers in 2011 [9], 1.3\% in the general population in the Netherlands (15-65 years) $[10,11]$ and $1 \%$ of the Norwegian youth aged 15-20 years [12]. Little is known about the exact prevalence of chronic GHB dependence in the USA and Europe due to the absence of surveillance and systematic reporting mechanisms [13]. Nevertheless, the number of GHB users seeking help has increased in recent years [9]. In the Netherlands, the number of patients admitted to addiction treatment centres for GHB detoxification quadrupled from 63 patients in 2008 to 799 patients in 2012 [14]; pertinent to this is the fact that GHB-related drug incidents increased substantially, e.g. $20 \%$ of the reported 3,652 drug incidents in the Netherlands in 2011 [7] and 7\% of the subsequent acute poisoning admissions in Norway [12].

The abuse potential of GHB is most likely the result of its anxiolytic, hypnotic and euphoric effects [15]. After the ban on the commercial trade of GHB, and its subsequent classification as a schedule $1 \mathrm{drug}$, abuse extended to $\gamma$-butyrolactone (GBL) and 1,4-butanediol $(1,4-\mathrm{BD})$ $[15,16]$. GBL and 1,4-BD are precursors of GHB, available as common industrial chemicals, and when ingested are rapidly metabolized into $\mathrm{GHB}$, exerting the same clinical effects as GHB [17]. GHB-dependent users who dose multiple times daily are repeatedly presented to emergency departments with acute intoxication, GHB withdrawal syndromes and GHB-related traumas [18]. Severe manifestations of GHB intoxication include central nervous system depression, hypoventilation, bradycardia, myoclonus and seizures. Agitation or delayed delirium may occur, as well as complications such as metabolic acidosis and Wernicke's encephalopathy, which may be lethal [19-21]. The clinical presentation of GHB withdrawal ranges from mild tremors, tachycardia, hypertension, anxiety, agitation, seizures and insomnia to profound disorientation, increasing paranoia with auditory and visual hallucinations, delirium, agitation and rhabdomyolysis [22]. The pharmacological and neurobiological mechanism of action of GHB responsible for its therapeutic and abuse-related effects is not entirely clear. However, over recent years an increasing number of animal studies and some human studies have focused on examining the mechanism of action of GHB. Several recent reviews have thoroughly addressed the neurobiology of GHB intoxication, e.g. van Amsterdam et al. [23]. Therefore, the aim of this review is to provide a neurobiological explanation of the complexity of GHB dependence and the GHB withdrawal syndrome and its clinical implications. In order to understand this complexity, firstly the effects of exogenous GHB (ExGHB) are reviewed by exploring the resemblances between the endogenous GHB (EnGHB) and the ExGHB neurobiological mechanism of action, and secondly, the neurobiological pathways of GHB dependence and withdrawal are explored.

\section{Endogenous and Exogenous GHB}

ExGHB was synthesized by Laborit [2] in 1960 as a potential $\gamma$-aminobutyric acid (GABA) agonist and analogue that induces sedation. It was later discovered that GHB is an endogenous compound existing in the brain of humans [24]. EnGHB concentrations in the human brain reach about 11-25 $\mu \mathrm{M}$ in the striatum [25], whereas the cerebellum and certain areas of the cerebral cortex contain the lowest concentrations [26]. ExGHB adds to these concentrations where GHB levels above the vitreous cutoff endogenous urine concentrations of $6-10 \mathrm{mg} / \mathrm{l}$ are considered to be exogenous [27, 28]. ExGHB seems to pursue almost the same neurobiological pathway as EnGHB with regard to metabolism and the neuronal uptake, release and degradation process in the brain, and it could be expected to provide equivalent physiological effects.

\section{Source and Metabolism}

EnGHB has several precursors: GABA, through transamination and reduction in the neuronal compartment by GABA transaminase and succinic semialdehyde reductase $[29,30], G B L$, as detected in the rat brain [1] and 1,4-BD, which exists among lipid-diols in the human brain [31]. ExGHB share the same precursors (fig. 1) [26]. When ingested in humans, ExGHB is absorbed rapidly and has a peak plasma concentration within 30-90 min
66

Neuropsychobiology 2016;73:65-80 DOI: $10.1159 / 000443173$
Kamal/van Noorden/Franzek/Dijkstra/ Loonen/De Jong 
Fig. 1. ExGHB and EnGHB metabolism. GABA is converted to succinic semialdehyde by GABA transaminase (in mitochondria), followed by a reduction of succinic semialdehyde to GHB by cytosolic succinic semialdehyde reductase. Succinic semialdehyde dehydrogenase converts succinic semialdehyde to succinate, leading to energy production via the Krebs cycle. GBL and 1,4-BD are converted to GHB and cross the blood-brain barrier. GHB oxidation takes place, forming succinic semialdehyde by $\mathrm{NADP}^{+}$-linked succinic semialdehyde reductase. The succinic semialdehyde undergoes further metabolism to either GABA or succinate. The GHB dehydrogenase is capable of metabolizing GHB to succinic semialdehyde. Another metabolism pathway of GHB is through a $\beta$-oxidation process. SSA $=$ Succinic semialdehyde; SSR = succinic semialdehyde reductase; $\mathrm{BBB}=$ blood-brain barrier.

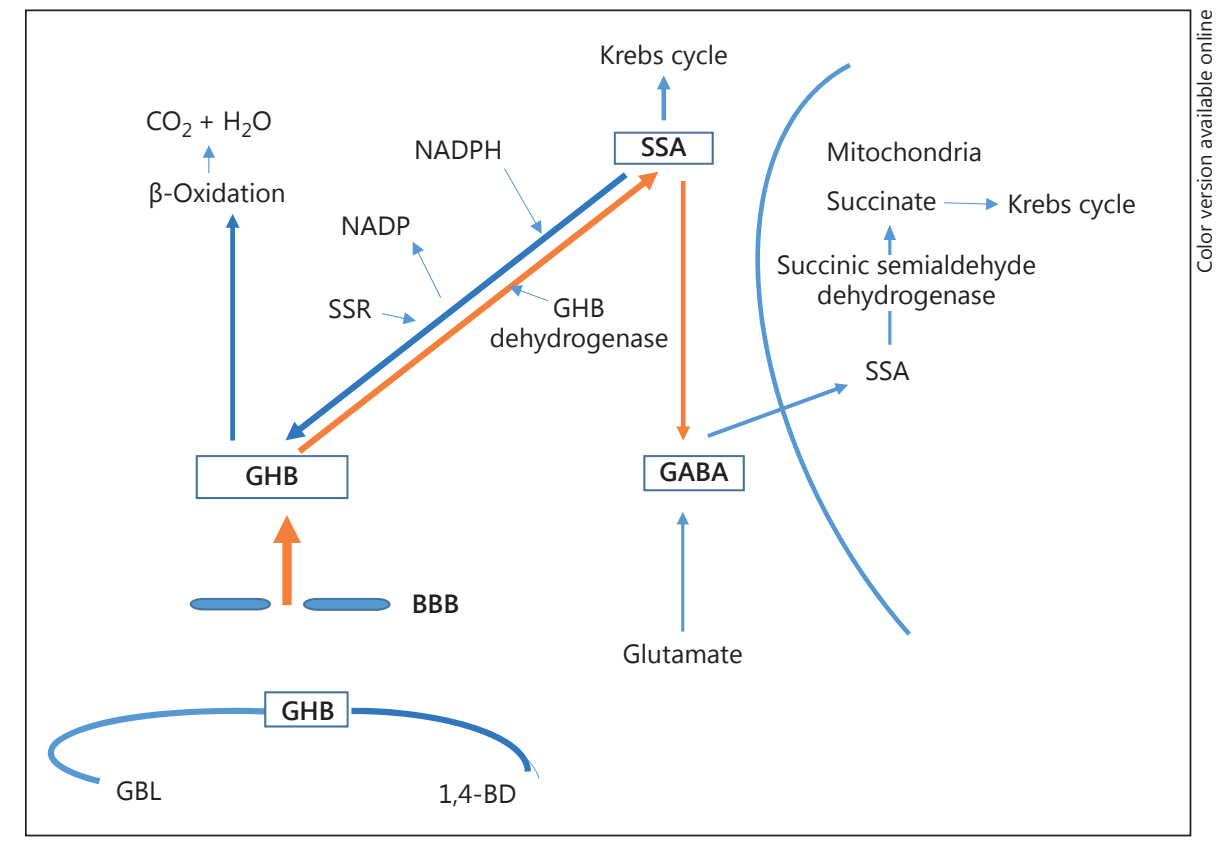

after ingestion [32]. The overload of the EnGHB system in the brain by the administration of ExGHB, which can easily cross the placenta and the blood-brain barrier [17] and penetrate into brain cells, will probably increase GHB concentration in the vesicles, depending on the threshold level of GHB in the neuronal cytosol [33]. ExGHB, as well as EnGHB, colocalizes with GABA in its nerve terminals $[26,33]$. It is released into the extracellular space by $\mathrm{Ca}^{2+}$ dependent neuronal depolarization from GHBergic terminals $[21,34]$. The elimination or degradation process seems to be similar for both EnGHB and ExGHB (fig. 1), and is strictly controlled by the negative feedback influence of the reaction products $[17,35]$. In addition, ExGHB has nonlinear dose-dependent renal clearance, which increases at higher GHB plasma concentrations [36], most likely due to the saturable reabsorption in the kidneys [37-39]. This may explain, in part, the renal failure process presentation during GHB intoxication, which might be fatal.

\section{Physiological Effect}

After crossing the blood-brain barrier, ExGHB in low doses could initiate the same physiological functions of EnGHB. This clarifies some of the interesting therapeutic perspectives of ExGHB, and may partially explain its unfortunate abuse liability. GHB levels are believed to rise in the case of hypoxia and/or ischaemia and excessive metabolic demand to protect central and peripheral tissues (e.g. myocardium) [1]. Results of animal studies demonstrate the direct protective action of GHB treatment against oxidative stress-induced cell death, apoptosis and nerve cell death mechanisms, which suggests that GHB may also control neuroprotection against transient global lesions [40-42]. This effect is achieved through reducing cell energy requirements and cerebral energy metabolism via the increase in brain concentrations of glycogen and glucose, and a decrease in concentrations of pyruvate, lactate and $\alpha$-ketoglutarate [1] which lowers oxygen demand and consumption by the brain and other tissues. Low levels of GHB also function as a feedback inhibitor of lipid peroxidation [43, 44]. This could explain the limited impact experienced by abusers following GHB-induced coma/blackouts, which leads to the inaccurate assumption of the drug's safety, thereby increasing its attraction and ultimate GHB abuse. On the other hand, and despite the suggested neuroprotective role, animal studies of repeated or prolonged exposure to GHB in rats showed noticeable neurological cell loss in the CA1 hippocampus and the prefrontal cortex [45]. Functional tests in rodents confirmed the presence of impairments in working and spatial memory [45-47], which can be lasting [48]. However, human studies systematically investigating the long-lasting effects of GHB use on cognitive functions are lacking. Another physiological function of GHB which has been beneficial therapeutically is its impact on the sleep pat- 
Table 1. Receptors mediating GHB effect [54, 65-67, 82, 136, 167]

\begin{tabular}{|c|c|c|c|}
\hline Description & $\begin{array}{l}\text { G-protein-coupled high- and } \\
\text { low-affinity GHB-binding } \\
\text { component }\end{array}$ & $\begin{array}{l}\text { Coupled to second messenger } \\
\text { systems and } \mathrm{Ca}^{2+} \text { and } \\
\mathrm{K}^{+} \text {channels via } \mathrm{G} \text { proteins }\end{array}$ & $\begin{array}{l}\text { Heterooligomeric } \mathrm{R} \text { ligand-gated } \mathrm{C} 1 \\
\text { channels, } \alpha \text {-, } \beta 1 \text { - and } \gamma \text {-subunits, and } \\
\rho \text {-subunits of GABA } \mathrm{R} \text {; homooligomeric } \\
\mathrm{R} \text { with intrinsic } \mathrm{C} 1 \text { channels }\end{array}$ \\
\hline High density & $\begin{array}{l}\text { Hippocampus (median raphe } \\
\text { nucleus and dentate gyrus), grey } \\
\text { matter cerebral cortex, NAc }\end{array}$ & $\begin{array}{l}\text { Cerebellum, thalamus followed } \\
\text { by hippocampus }\end{array}$ & $\begin{array}{l}\text { Hippocampus and cortex, cerebellum, } \\
\text { retina and Xenopus oocytes }\end{array}$ \\
\hline GHB effect & High-affinity full agonist & Low-affinity full agonist & $\begin{array}{l}\text { Full agonist and with some subtypes; } \\
\text { partial agonist }\end{array}$ \\
\hline Behaviour effect & Physiological: sleep and memory & Addiction & Sleep, decreased anxiety \\
\hline Other agonists & NCS-356 & Baclofen and CGP-27492 & Benzodiazepines, TACA \\
\hline
\end{tabular}

tern in humans and rodents. This effect could be one of the potential risks for the abuse and dependence liability of GHB when used as self-medication, especially in patients suffering from sleep disturbances. Just as EnGHB plays an important role in sleep physiology [49], ExGHB also counteracts sleep latency and promotes deep slowwave non-REM sleep $[44,50]$, e.g. in depressed patients [51]. Human consolidation of sleep [52] with doses as low as $0.32-0.56 \mathrm{~g} / 70 \mathrm{~kg}$ plasma concentration should be considered [53]. This effect is produced via the stimulation of the GHB-specific receptors (GHBR), for which GHB has a high affinity [54]. GHBR has an ontogenetic molecular identity profile distinct from $\mathrm{GABA}_{\mathrm{B}}$ receptors $\left(\mathrm{GABA}_{\mathrm{B}} \mathrm{R}\right)$ and different subtypes [55]. In the median raphe nucleus and the dentate gyrus of the hippocampus, one of the regions with the highest expression of GHB high-affinity binding sites, as well as in several brain regions involved in sleep physiology, GHB but not baclofen as a pure $\mathrm{GABA}_{\mathrm{B}}$ agonist induced c-Fos expression $[56,57]$. GHB in nano- to micromolar concentrations [58] exerts effects via the GHBR high-affinity site, and is suggested to be counteracted by the GHBR antagonist NCS-382 [56]. Some studies have stated, in contrast, that pretreatment with NCS-382 potentiated, rather than antagonized, a GHB-induced sedative hypnotic effect [59], which was offset by others who questioned the antagonistic properties of NCS-382 on GHBR since it failed to block the effect of GHB on hypomotility and sedation/hypnosis [60-62]. The involvement of GHBR was confirmed when the specific GHBR agonist c-hydroxyvaleric acid was proved to mimic the sedative effects of $\mathrm{GHB}$ without binding to the $\mathrm{GABA}_{B} \mathrm{R}[58,63]$. Higher supraphysiological concentrations (such as ExGHB) downregulate the GHBR and eliminate the tonic inhibitory control of GHBR on the GABA presynaptic element. As a result, both GABA release and GABAergic tone increase, inducing sleep [64]. Nevertheless, the exact involvement of GHBR is still unclear. The effects of GHB on sleep, as has been suggested, have to be mediated by the $\beta_{1}$-subunit containing the $\alpha_{4}-\mathrm{GABA}_{\mathrm{A}}$ receptor $\left(\mathrm{GABA}_{\mathrm{A}} \mathrm{R}\right)[65,66]$ which is highly sensitive to low concentrations of GHB (levels of 1.0 $\mu \mathrm{M}$ GHB or below in neuronal level); when the concentration increases an additional $\mathrm{GABA}_{\mathrm{A}} \mathrm{R} \delta$-subunit would putatively become involved $[66,67]$. In summary, GHB ingested in low doses could initiate some physiological effects mediated mainly by GHBR, the $\beta_{1}$-subunits of $\alpha_{4}-G_{A B A} R$. These effects which have positive therapeutic functions may unfortunately provide a potential risk for abuse. Studies presenting the exact GHB concentration needed to produce all of these effects in humans are lacking (table 1).

\section{Characteristics of Behavioural Effects of ExGHB}

A special characteristic of GHB is the nonlinear oral absorption with limited capacity at higher doses $[52,68]$. This leads to an increased interval of time to achieve 
$\mathrm{T}_{\max }$ and a decrease in the normalized $\mathrm{C}_{\max }$; for example, the average time to achieve peak concentration increased from $25 \mathrm{~min}$ at a dose of $12.5 \mathrm{mg} / \mathrm{kg}$ to $45 \mathrm{~min}$ at a dose of $50 \mathrm{mg} / \mathrm{kg}[17,35]$. The mean peak plasma concentration decreases with the presence of food in the stomach. GHB can be behaviourally active at doses as low as $0.32 \mathrm{~g} / 70 \mathrm{~kg}$ within 10-20 min after ingestion, with a short duration of action [53]. Higher doses (e.g. 0.56 g/70 $\mathrm{kg}$ ) produce a longer duration of action $[32,53]$, thus an abrupt and dose-dependent effect. Furthermore, GHB effects are biphasic, with initial stimulant-like effects followed by a mixture of sedation and stimulant-like effect as blood concentrations rise [69]. All of the above can explain the abuse pattern and the repeated GHB administration in doses between supraphysiological and pharmacological levels per ingestion at a maximum interval of $4 \mathrm{~h}$ to achieve the targeted reward effect every time.

\section{Neurobiological Pathway of GHB Dependence}

\section{Dose and Intensity of GHB Use in Relation to Dependence}

When GHB is administered in therapeutic doses, such as 3-9 g/night or day for the treatment of narcolepsy or alcohol dependence, the development of tolerance to the effect of GHB is unlikely to occur [70,71]. In these studies, signs of physical dependence or symptoms of withdrawal after discontinuation were not reported $[15,72-74]$. On the other hand, studies in baboons showed that lower doses such as $56 \mathrm{mg} / \mathrm{kg}$ can induce possible drug abuse effects $[70,75]$. Repeated administration of GHB at least 3-6 times per day can lead to tolerance and dependence on the behavioural and neurochemical effects with apparent withdrawal symptoms $[26,76]$. In humans, physical dependence has been described within days to weeks of frequent and heavy use [76-78]. The average self-administered dose reported in dependent patients ranges from 32-67.2 g/day [79] to a maximum of $144 \mathrm{~g} /$ day [77] at intervals of $45 \mathrm{~min}$ to $2.5 \mathrm{~h}$. The severity of physical dependence on GHB is also a function of the dose and duration of abuse [80]. Thus, not unexpectedly, high doses and/or longer periods of dosing may be critical for physical dependence on GHB [70, 79].

\section{GHB Dependence Liability}

GHB use is considered to have a high dependence potential. It may be related to the reward mechanisms involved and the self-medication use patterns.

Neurobiology of GHB Dependence and Withdrawal
Reward Mechanism of GHB

GHB shares the neuronal circuits that are believed to mediate the rewarding and drug-seeking behavioural aspects of most abused drugs including mesolimbic dopaminergic and glutamatergic neurons in the ventral tegmental area (VTA) and the nucleus accumbens (NAc) [81-84]. Besides mediating rewarding effects, the activation of the mesolimbic dopamine system is also thought to be centrally involved in the induction of repetitive drug use [85]. GHB seems to have distinguishable pathways in these neurological processes which contribute to its dependence liability. GHB has a bidirectional effect on the $\mathrm{GABA}_{\mathrm{B}} \mathrm{R}$, influencing the GABA neurons and dopamine neurons in opposite ways. $\mathrm{GHB}$ can indirectly reduce the excitability of the NAc. GHB has a recognized impact upon glutamate transmission levels and a neuromodulator effect on serotonin.

$G H B$ Bidirectional Effect on $G A B A_{B} R$ and GABAergic Neurons Facilitate Dopamine Release. The properties of dependence/tolerance and behavioural effects of GHB seem to be consistent with the involvement of the GABAergic receptors, mostly the $\mathrm{GABA}_{B} \mathrm{R}[61,86,87]$. $\mathrm{GHB}$ activates the $\mathrm{GABA}_{B} \mathrm{R}$ directly or indirectly through the metabolic conversion of GHB to GABA and the GHBmediated feedback control of GABA release [21, 67]. Subtypes of the $G_{A B A} R$ (subunits $G_{A B A}$ and $G_{B A A}$ ) are important in mediating the effects of GHB [21, 8892]. GHB is distinguished by its discriminative stimulus properties on $\mathrm{GABA}_{B} \mathrm{R}$, despite the low-affinity partial agonist character [85, 87]. GHB has a bidirectional effect on the $\mathrm{GABA}_{\mathrm{B}} \mathrm{R}$ [85], leading to opposite effects: an increasing (stimulating) effect on one side and a decreasing (inhibitory) effect on the other side. This effect depends on the localization of the $\mathrm{GABA}_{B} \mathrm{R}$ and the type of the Gprotein-dependent ion inwardly rectifying potassium (GIRK) channel subunits, which mediate the inhibitory effects of G-coupled receptors like $G_{A B A} R$ [93]. The GIRK channels are responsible for maintaining the resting membrane potential and excitability of the neuron. Once the $\mathrm{GABA}_{\mathrm{B}} \mathrm{Rs}$ are activated, they allow for the dissociation of the $G$ protein into its individual $\alpha$-subunit and $\beta \gamma$-complex, so it can in turn activate the $\mathrm{K}^{+}$channels. The $G$ proteins couple the inward rectifying $\mathrm{K}^{+}$ channels to the $\mathrm{GABA}_{\mathrm{B}} \mathrm{R}$, mediating a significant part of the GHB inhibition effect [94].

It has been shown that there is differential coupling efficacy (EC50) of GIRK channels in the VTA neurons; that is to say, the cell-specific expression of GIRK in VTA neurons can differ with respect to $1,2 \mathrm{c}$ and 3 GIRK subunits. Mostly GIRK1/2 heteromultimeric channels are

Neuropsychobiology 2016;73:65-80 
expressed at the surface in GABA neurons and GIRK2c/3 is expressed in dopamine neurons $[85,95,96]$. This difference in the coupling between $\mathrm{GABA}_{B} \mathrm{R}$ and GIRK subunits provides a mechanism for generating that bidirectional modulation effect of GHB on the neuronal mesolimbic dopamine system. Due to the increased efficiency or full activation of the GIRK channel subunits (1/2) coupling to the $\mathrm{GABA}_{\mathrm{B}} \mathrm{R}$ in the presynaptic GABAergic neurons, these neurons are more sensitive to $\mathrm{GHB}$, and can be targeted even at low doses of GHB as agonist $[55,85]$. Despite that, these GABAergic neurons normally exert an inhibitory effect on the dopaminergic neuronal activity. The GHB activation of GIRK channels on GABA interneurons suppresses their spontaneous activity and leads to disinhibition of the dopamine neurons, increasing their firing rate and enhancing VTA dopamine output [97]. In other words, GHB activation of the presynaptic $\mathrm{GABA}_{\mathrm{B}} \mathrm{R}$ inhibits GABA release and this, in turn, disinhibits dopaminergic neuronal activity. GHB also lowers the tone in the GABAergic neurons, decreasing the firing rate of the postsynaptic neurons [81]. This can lead indirectly to disinhibition of dopamine neurons. GHB also promotes the release of dopamine postsynaptically [26, 53] as putative GHB-producing neurons are surrounded by dopaminergic terminals, suggesting a direct interaction between GHB and dopamine [98].

In mice, repeated exposure to $\mathrm{GHB}$ increased the $\mathrm{GABA}_{\mathrm{B}} \mathrm{R}$ GIRK channel coupling efficiency in the dopamine neurons through the downregulation of the regulator of $\mathrm{G}$ protein signalling-2 (RGS-2), a member of the RGS protein family [93], another mechanism that might be associated with tolerance.

In summary, GHB leads to the suppression of the spontaneous activity of the GABA neurons through decreased transmitter release (presynaptic inhibition) and concomitant hyperpolarization (postsynaptic inhibition), besides an opposite direct effect on the dopamine neurons. These pathways cause disinhibition of the dopamine neurons, especially in the VTA, which provides an explanation for its strong abuse potential. Added to that, GHB in high doses is metabolized at first to succinic acid. A sufficient amount of succinic acid is formed within the brain to inhibit the formation of GABA from glutamate, and results in lowered concentrations of GABA [34, 52]. Thus, the GABA system is downregulated, and its ability to inhibit neurotransmitter release is reduced. The foregoing, especially the activation of the mesolimbic dopamine system, can explain the increased reward addictive process which accentuates craving and GHB-seeking behaviour.
GHB Affects Glutamate Transmission and Controls Hippocampal and NAc Glutamate Levels. Glutamate plays a key role in modulating both the progress of the sensitization of addiction behaviours and their expression such as drug-seeking [83]. Exogenously applied GHB controls hippocampal glutamate levels in a concentration-dependent manner. It is reported that the systemic administration of low doses of GBL, as a precursor of $\mathrm{GHB}$, augments long-term potentiation/depolarization, causing transient plasticity in the CA1 intrahippocampal region and, mediated by GHBR activation, increases hippocampal glutamate transmission [99-101]. GHB in millimolar concentrations exerts the same effect $[100,102]$ mediated by the N-methyl-D-aspartate receptor (NMDAR)-gated ion channel [103]. There is an intrinsic connectivity between the hippocampus, known for its role in long-term memory, and the midbrain (VTA) dopamine regions and the NAc, known for their role in motivation and reward processing [104]. It is also speculated that the dopamine receptor (D1)-mediated increase of NMDA current on the dopamine neurons cause a rise in presynaptic glutamate release and elevate the activity of prefrontal glutamatergic input to the VTA [83] - a sequence of synaptic events which induce GHB addiction-related behavioural sensitization. Glutamatergic plasticity in the NAc is critical for the expression of these behaviours [105]. GHB could indirectly reduce glutamate transmission via a bidirectional effect on the presynaptic glutamatergic $\mathrm{GABA}_{B} \mathrm{R}$, where the heteroreceptors are more sensitive to GHB than the autoreceptors [106]. Therefore, the repeated engagement in GHB drug-seeking might, as with other drugs, cause an enduring imbalance in glutamate homeostasis in the NAc, leading to a progressively greater reliance on the motor subcircuit and a reduced influence of the limbic subcircuit [107]. In conclusion, the effect of GHB in glutamate release and transmission contributes to GHB addiction behaviour sensitization and expression by enhancing the memory of reward and the accompanied excitation effect.

GHB Has an Indirect Effect on the NAc Neurons. GHB shares with other drugs of abuse the ability to reduce the excitability of the NAc neurons, which contribute to its abuse potential $[55,81]$. Conversely, GHB differs as it has no direct $\mathrm{GABA}_{\mathrm{B}} \mathrm{R}$-mediated effect on the medium spiny neurons of the NAc, as stated by Molnár et al. [62]. Thus, the reduced activity of NAc observed after systemic GHB administration [81] is related to an indirect effect of the cortical and limbic inputs outside the NAc. There, GHB activates post- and presynaptic $\mathrm{GABA}_{\mathrm{B}} \mathrm{Rs}$, hence hyper- 
polarizing cells and decreasing their glutamate-mediated synaptic responses [108], and then merging into the NAc and increasing the release of dopamine into the rewardmediating NAc area [85]. This is in addition to a GHB main cellular effect in the NAc, executed via a repetitive transient elevation of astrocytic $\mathrm{Ca}^{2+}$-independent neuronal signalling $[62,109]$. This in turn leads to neuronal hyperpolarization and suppresses baseline excitatory synaptic activity [110], a reaction which has been proven to be mediated by a putative novel GHB agonist-specific and succinate-sensitive but NCS-382-insensitive receptor in the astrocytic target [109]. This ability of GHB achieved at a lower dose than the concentration necessary to activate $\mathrm{GABA}_{\mathrm{B}} \mathrm{R}[55,62]$ is a powerful means for the rapid modulation of network activity, which can explain the rapid process and intense reward dependence effect of GHB.

The main reward pathway of $\mathrm{GHB}$, as we mentioned earlier, is through its effect on GABA and glutamate. However, GHB is also suggested to have a neuromodulator effect on serotonin, adding to the experienced reward effect and dependence liability potential.

Effect of GHB on Serotonin Amplifies Reward. Animal studies imply that GHB in pharmacological and recreational doses induced an increase in serotonin turnover associated with a rapid intracellular metabolism, which may explain the absence of an increase in serotonin [97, $111,112]$. A decrease in the extracellular concentration of serotonin was observed [111], probably due to intraneuronal deamination of newly synthesized serotonin which remains in the cytoplasmic pool. The GHB effects mediated by GHBR increase tryptophan and its uptake in brain tissue by facilitating the dissociation of tryptophan from its albumin binding sites $[1,111,113]$. On the other hand, a $\mathrm{GABA}_{\mathrm{B}} \mathrm{R}$ dual control of dorsal raphe serotonergic neuronal activity has been suggested, which appears to be similar to that exerted on dopaminergic neuronal activity $[44,114]$. An interrelationship between the serotonergic and dopaminergic systems, where dopamine release has been shown to be increased by serotonin, is suggested and confirmed by the described projections from the substantia nigra and the VTA to the dorsal raphe nucleus and in the striatum $[111,115]$. This can produce a direct inhibitory effect on GABAergic terminals or interneurons and an indirect excitatory state [116], contributing to the rewarding euphoric effect of GHB.

\section{Neurobiology of Self-Medicating with GHB Use}

GHB also has a neuromodulator effect on several other neurotransmitters and neurohormones which may ex- plain its self-medicating use and may add to its high dependence liability.

Effect of GHB on Adrenergic Activity and Growth Hormones. The sustained daily administration of GHB for 2 - and 10-day periods in rats decreased both the spontaneous firing rate and the evoked burst firing of the locus coeruleus adrenergic neurons [44, 117]. This attenuation of an adrenergic neuron firing rate may be important to the anxiolytic and sedative effects associated with GHB. The exact mechanism by which GHB elicits its effects on these neurons is not clear. However, the ability of GHB to activate $\mathrm{GABA}_{\mathrm{A}} \mathrm{R}$ and $\mathrm{GABA}_{\mathrm{B}} \mathrm{R}$, which has been identified on adrenergic neurons [114], may partially explain this effect. GABA tonically inhibits cortical cholinergic neuronal activity [118]. GHB in repeated recreational doses mediated by $\mathrm{GABA}_{\mathrm{B}} \mathrm{R}$ inhibits GABA and could subsequently increase cholinergic activity. GHB seems to increase the acetylcholine content in several rat brain regions, including the hippocampus, and reduce extracellular levels of acetylcholine [119]. This suggests that GHB reduces cholinergic neurotransmission effective in stress conditions and contributes to its anxiolytic effect, and hence to its abuse potential.

The effect of GHB on the cholinergic system can subsequently result in a change of growth hormone levels. GHB-induced growth hormone secretion in humans [120] is due to the stimulation of not only the cerebral $\mathrm{GABA}_{\mathrm{B}} \mathrm{R}$ [119] but also the specific pituitary GHBR [121]. The stimulating effect of GHB on growth hormones seems to correlate with its capacity to induce slowwave sleep $[122,123]$. This can contribute to its appeal for abuse amongst youth [124].

GHB Neuromodulates Neurosteroids and Oxytocin. The decrease in neurosteroids and $\alpha_{4} \beta_{1} \delta$-GABA ${ }_{A} R$ upregulation has been associated with increased anxiety $[66$, 125]. Experiments in rats have suggested that GHB positively modulates $\mathrm{GABA}_{\mathrm{A}} \mathrm{R}$ and NMDAR, leading to an increase in the synthesis of neuroactive steroids, such as the centrally synthesized progesterone analogues allopregnanolone and allotetrahydrodeoxy corticosterone $[126,127]$. This modulation can also explain the anxiolytic effect of GHB. GHB has been shown to reduce hypothalamus-pituitary-adrenal axis hyperactivity in humans, which may lead to a decrease in stress hormones (e.g. corticotropin-releasing hormone) and an increase in oxytocin. The effect of oxytocin is also facilitated by interactions with the mesolimbic dopamine system [122]. The stimulation of oxytocin neurons might be one of the mechanisms by which the GHB modulates the dopaminergic tone. Both neurosteroids and oxytocin have been 
discussed as playing a critical role in the regulation of social and sexual behaviour, anxiety, stress, aggression and the modulation of depression [128].

Effect of GHB on the Opioid System. Despite the fact that the exact interactions between GHB and the opioid system are poorly understood, and no direct stimulation of $\mu$-, $\delta$ - and $\kappa$-receptors could be shown, the GHB dopamine release in the striatum is possibly accompanied by the release of endogenous opioids. This indicates a certain opioidergic analgesic and sedative effect of GHB which can be antagonized by naloxone $[23,129,130]$. All the aforementioned deliberated self-medication, anxiolytic, antidepressant and sedative effects of GHB, while forming a part of its therapeutic potential, do however contribute to and play an important role in its potential addiction liability risk.

\section{GHB Abuse versus Medical Use}

Despite the fact that the neurobiological mechanisms presented also apply to medically used GHB, studies have shown that patients using GHB medically have very low abuse liability [15]. This could be explained in some cases, such as for example in narcolepsy patients, by the exhibited deficiency in the hypocretin/orexin system in the form of a decrease in mutations of the hypocretin/orexin gene, peptide and neurons. The hypocretin/orexin system plays a role in the activation of the mesolimbic dopamine system. This deficiency leads to a reduction of pleasure associated with reward processing, effects of addictive drugs and risk-taking behaviour [131-133]. This might provide an explanation for the limited abuse potential in narcolepsy patients. In general, it seems that GHB dependence associated with withdrawal symptoms is exhibited in animal models and human cases [131] when high doses with a minimum of 11-18 g/day [77, $134]$ are used in an 'around the clock' frequency pattern [135], which is not the case in the daily regime of 1-2 doses applied in most therapeutic interventions.

\section{Neurobiological Effects of Chronic GHB Abuse}

The action of GHB during chronic abuse in the mesolimbic system is suggested to be mediated mainly through $\mathrm{GABA}_{\mathrm{B}} \mathrm{R}[81,82]$. Nevertheless, the involvement of GHBR in other brain regions (such as the hippocampus) cannot be excluded [100]. Chronic GHB exposure desensitizes $G H B R$ and $G A B A_{B} R$, thus reducing their ability to affect neurotransmitter release [136]. Chronic GHB abuse can affect the most important neuroregulators. It downregulates the GABA system. Chronic GHB abuse firstly increases the glutamate level, subsequently decreasing the maximal density of NMDA binding sites, and downregulates NMDAR (e.g. in the frontal cortex) $[47,107]$. By repeated exposure to higher doses of GHB, the dopamine neurons would be directly hyperpolarized, resulting in a decrease in VTA dopamine release [55, 85] accompanied with an upregulation of D1 and D2. Chronic treatment of rats with GHB showed an increase of mRNA expression of dopamine D1 and D2 receptors in brain regions that are rich in GHBR [137], and the development of tolerance to the effect of GHB on brain dopamine levels, thus the mesolimbic dopamine system becomes 'hypofunctional' in the GHB-dependent brain. Increased serotonin turnover in chronic GHB abuse can lead to more inhibition in dopamine concentration in the brain [97], as well as reduced noradrenergic and cholinergic activity [117].

In addition to these main effects mentioned of chronic GHB misuse, GHB displays partial agonism at $\alpha_{4} \beta_{1} \delta$ receptors compared with GABA, but does not replace the GABA effect, and in the case of chronic GHB abuse $\alpha_{4} \beta_{1} \delta$ $\mathrm{GABA}_{\mathrm{A}} \mathrm{R}$ can be upregulated due to the decreased GABA effect [66]. The neurosteroid effect can increase as the $\alpha_{4} \beta_{1} \delta$-subtype has been identified as an important target for neurosteroids. Finally, the possible involvement of the extrasynaptic subtypes of $\mathrm{GABA}_{\mathrm{A}} \mathrm{R}$ may explain the sedative effect during chronic GHB abuse despite the low GABA concentration. Chronic abuse is also associated with sustained opioid release.

\section{Possible Neurobiological Mechanism of Withdrawal}

The discontinuation of GHB intake in chronic dependent abusers reverses the neurobiological effect of GHB and produces a variety of (adverse) withdrawal symptoms. Due to the previously mentioned effects of GHB on GABA and glutamate which reflects on the different neurotransmitter systems, the state observed during withdrawal is likely to be the result of a complex interaction.

The withdrawal syndrome consists of several symptoms which may persist for several days. In the initial period of abstinence, features include physical symptoms and signs such as tremors, miosis, sweating, tachycardia, palpitations, dyspnoea, nausea, vomiting, diarrhoea, abdominal pain and prevailing anxiety-related behaviour $[76,77,138]$. These are related to the stimulation of the
Kamal/van Noorden/Franzek/Dijkstra/ Loonen/De Jong 
sympathetic system due to an increase in noradrenaline and acetylcholine as the result of an impairment of the feedback inhibition of GABA. In a study on rats, a significant 33\% increase in spontaneous noradrenergic neuronal activity and a robust $79 \%$ increase in burst firing were found to be due to GHB withdrawal [117]. The loss of GHB ability to attenuate the locus coeruleus activity increases noradrenaline [117] and may be important in causing anxiety during withdrawal.

In addition, the upregulation of $\alpha_{4} \beta_{1} \delta$-GABA ${ }_{A} R$ has been associated with increased anxiety and hyperalgesia because of disinhibition of the GABAergic neuronal output [66]. Part of the occurrence of arousal symptoms such as anxiety during GHB withdrawal can also be explained by the decrease in neurosteroid concentration, which is a positive allosteric modulator of the $\mathrm{GABA}_{\mathrm{A}} \mathrm{R}$ and NMDAR [55, 127, 128, 139].

It has been suggested that, after the chronic abuse of drugs, dopamine release is compromised. Studies have pointed to the relevance of dopamine in withdrawal. It has been documented that, during withdrawal, striatal dopamine response or receptor availability was significantly low in cocaine abusers [140], and the striatal D2 receptor was downregulated in alcohol and heroine abusers $[141,142]$. This neurological state seems to be different in the case of GHB, and the low dopamine level is reversed rapidly to a high level after the cessation of GHB. The increase may persist and explain the latent psychosis/ delirium within 2-4 weeks after withdrawal/abstinence $[22,143]$.

In more severe cases of withdrawal, patients experience symptoms such as hypertension, insomnia, agitation, paranoia, disorientation, confusion, aggression and auditory and visual hallucinations [76]. These symptoms are (probably) mainly due to a sudden increase of dopamine concentrations in the frontal cortex and thalamus associated with the presence of D1 and D2 upregulation status, an effect which can be hypothesized to be related to the increased activity of the hippocampal neurons and the inhibited effect of prelateral frontal cortex projection through D2 receptors [144] and the reduced GABAergic transmission [88]. Due to these mechanisms, as well as to the associated manipulation of serotonin levels [115], patients may also suffer from depression and, in severe cases, they develop delirium and/or psychosis. One of the withdrawal complications of GHB described is an excited delirium syndrome. The clinical findings often include tachypnea, sweating, severe agitation, elevated temperature, delirium, non-compliance to and poor awareness of instructions, and lack of fatigue with unusual strength

Neurobiology of GHB Dependence and Withdrawal and pain tolerance $[145,146]$. This state can be explained by the persistent dopamine increase together with serotonin dysregulation, and it does not react upon the administration of antipsychotics. Impairment of the sleepmediating effects of GHB via the $\beta_{1}$-containing $\mathrm{GABA}_{\mathrm{A}} \mathrm{R}$ leads to insomnia [66]. The thermic effects of GHB withdrawal are dose dependent, and can occur due to a decrease in metabolic heat production and/or an increase in cutaneous circulation $[1,91]$. The recognizable symptoms here are hyper- or hypothermia, tremors and reflex sweating. Likewise, due to the modulation of serotonin, uncontrolled muscle contraction caused by hyperkinesia and clonus takes place; in some studies, seizures were also observed $[22,76]$. A serotonin syndrome-like state is generated. The low pain threshold observed, e.g. muscle pain and skin sensitivity, are possibly due to a decrease in the enhancement of endogenous opioid release. Furthermore, a reverse of the inhibition of cholinergic neuronal activity is followed by a significant increase in acetylcholine and noradrenaline levels [119]. These can slow down depolarization and increase neuronal excitability, resulting in irregularities in the heart rate and blood pressure, precipitating anxiety and insomnia, an increase in locomotor activity and the production of lactate and other toxins from skeletal muscle [117]. Besides the previously mentioned serotonin effect, the latter may cause rhabdomyolysis and finally lead to renal malfunction.

In summary, the withdrawal complications could be related to the increase in sympathetic activity, dopamine and serotonin, a decrease in opioids and the prolonged downregulation of the GABA system. Thus, during GHB withdrawal, GABA alone, as the most inhibitory neuroregulator of the brain, is no longer capable of opening the ion channels. On the other hand, glutamate, as the dominant excitatory factor, undergoes dysregulation in addition to increases in both dopamine and serotonin levels in the brain. This is associated with the upregulation of D1, D2, NMDR and GABA $\mathrm{A}$. All the aforementioned result in cellular hyperexcitability that is easily stimulated by excitatory postsynaptic potentials, which are thought to be responsible for the previously mentioned complex withdrawal state (table 2).

\section{Clinical Implication on Withdrawal Treatment and Relapse}

The complexity of the neurobiological pathways and the involvement of several receptors and neurotransmitters are repeatedly translated into severe withdrawal pre- 
Table 2. Possible neurological explanations for GHB withdrawal symptoms and signs

\begin{tabular}{|c|c|}
\hline Withdrawal symptom & Possible main neurotransmitter effect \\
\hline Auditory/visual hallucinations, paranoia & + Dopamine \\
\hline Tremors & + Acetylcholine, serotonin \\
\hline Tachycardia/palpitations & + Acetylcholine, + noradrenaline \\
\hline Hypertension & + Noradrenaline \\
\hline Sweating/hyperthermia & + Dopamine, + noradrenaline, - serotonin \\
\hline Anxiety & - GABA, + glutamate, - neurosteroids, fluctuating serotonin \\
\hline Agitation/aggression & + Serotonin, + glutamate \\
\hline Pain & - Opioids \\
\hline Insomnia/sleeping disorder & - GABA, + dopamine \\
\hline Disorientation/delirium & + Dopamine, + noradrenaline , - GABA \\
\hline Depressive reaction & - Serotonin, - neurosteroids, GABA \\
\hline Hypothermia/hyperthermia & + Dopamine \\
\hline Muscle contractions/convulsions & + Acetylcholine, - GABA \\
\hline
\end{tabular}

sentations and inconsistent treatment approaches. The abrupt cessation of long-term, high-dose GHB abuse can rapidly lead to a severe uncontrolled situation, e.g. psychosis and aggression. A prolonged withdrawal state has been reported, lasting up to 3 weeks in several cases [77, $138,147,148]$ and in some patients for 4 weeks to months [134], a state which is characterized by disorientation, depression, anxiety, panic attacks and insomnia [77, 134]. The intensity of the withdrawal symptoms can urge abusers to maintain their illicit GHB levels by redosing frequently and around the clock [21], sometimes risking the danger of overdose and intoxication. Severe withdrawal symptoms such as aggression and agitation have, in some cases, been effectively treated with benzodiazepines such as the $\mathrm{GABA}_{\mathrm{A}}$ agonist $[135,143,149]$. In numerous other cases, however, a resistance to benzodiazepines was reported and the delirium/psychosis and agitation state persisted despite the particularly high dosages of benzodiazepines, e.g. daily doses of diazepam $230 \mathrm{mg}$ [79] or lorazepam $22.5 \mathrm{mg}$ i.v. [138]. Treatment alternatives such as antipsychotic agents have been considered and caused a neuroleptic malignant-like syndrome state [150]. Barbiturates have been suggested [151] due to their ability to directly open both the $\mathrm{GABA}_{\mathrm{A}} \mathrm{R}$ and, for a longer duration, the voltage-gated chloride channels [149]. Pentobarbital and phenobarbital also have an antiglutamatergic effect via the AMPA (amino-3-hydroxy-5-methyl4-isoxazolepropionic acid)/kainate receptors [152], and might lead to a decrease in the high glutamatergic state during withdrawal. Baclofen as a $\mathrm{GABA}_{\mathrm{B}}$ agonist can also have a role in the treatment. The difference in the abuse liability of GHB and baclofen may be explained by the differential coupling of $\mathrm{GABA}_{\mathrm{B}} \mathrm{R}$ to GIRK channels $[26,85$, 153]. In contrast to $G H B$, baclofen, due to its high affinity for the $G_{A B A} R$, would at typical therapeutic levels inhibit both GABAergic and dopaminergic neurons and decrease dopamine release [85]. However, clinicians should consider the danger of a rapid dose which could induce psychosis and aggravate the withdrawal symptoms, as has occurred in some cases [154]. Benzodiazepine-resistant cases were successfully and safely treated with pharmaceutical GHB titration and tapering [155].

Nevertheless, GHB-dependent patients report high relapse rates shortly after $\mathrm{GHB}$ detoxification treatment [156], which could be related to an increased impulsivity reaction. Despite the fact that it is clear that impulsivity is probably multifarious, where different aspects may contribute to different clinical syndromes, it is proposed that the balance between serotonin and dopamine transmission is critical in the aetiology of impulse control $[157,158]$. An abnormal increase in dopamine transmission at D2 and D3 receptors, e.g. treatment-induced impulsivity in Parkinson's disease patients $[159,160]$ and serotonin disbalance or decrease, can increase impulsivity (impulsive choice) in humans. This is a state present during the GHB withdrawal phase and may persist for weeks. The impulsive behaviour in this case is characterized by impatience to delayed rewards (increased delay discounting) and an increased likelihood of premature responding $[161,162]$. At the same time, other neu- 
rotransmitters are thought to play a role here [162] such as, for example, manipulations of the noradrenergic system [163] and the decreased GABA levels in the dorsolateral prefrontal cortex [164] also presented during withdrawal. Thus, it could be expected that within a period of several weeks after detoxification, GHB-dependent patients might show an impaired capacity to inhibit their premature responses, a tendency towards risky decision making and a disregard for the relative value of delayed rewards, which may play a prominent role in the reported relapse behaviour.

\section{Discussion and Conclusions}

GHB has become a popular drug in Europe over recent decades [7]. This popularity has resulted in an increase in GHB intoxication and, more recently, dependence. GHBdependent patients repeatedly suffer from a complicated withdrawal syndrome which can be life threatening [18, 22 ] and challenging to treat. Therefore, in this review we aimed to follow the neurobiological pathway responsible for GHB dependence and to provide an explanation for the complexity of the withdrawal syndrome. Recent years have seen important developments in our understanding of GHB neurobiology, and some of the key cellular mechanisms of its actions have been revealed. The EnGHB signalling system in the brain can be easily, and similarly, stimulated by the peripheral administration of GHB, which follows almost identical metabolism routes and neurobiological pathways accountable for some of its therapeutic effects. The mechanism of action of ingested GHB is distinctive from many other drugs with dependence properties, since it is distinguished by its bidirectional discriminative stimulus properties on $G_{A B A} R$. This can induce mainly GABAergic inhibition and dopamine disinhibition. GHB does not lack a direct effect on the GABAergic neurons and glutamatergic pathways in the NAc, but it reduces the activity of the NAc through an indirect pathway producing cortical and limbic inputs outside the NAc. GHB is suggested to cause an elevation of the astrocytic $\mathrm{Ca}^{2+}$-dependent neuronal signals within the NAc, which explains the rapid rewarding effect of GHB [62]. Several factors contribute to the potential GHB dependence liability, for instance the self-medication role in sleep regulation, the high rewarding euphoric state, and the anxiolytic and depression-modulating effect. The aforementioned confirm that GHB can be highly addictive, with an intensive pattern of abuse, and has an obvious impact on the psychological state of the pa-

Neurobiology of GHB Dependence and Withdrawal tients. Chronic GHB abuse, as presented in animal (rat) studies, may lead to the downregulation of the GABA system [52] and to the upregulation of dopamine receptors D1 and D2 [137], and is also associated with upregulated NMDAR [100]. Chronic GHB abuse modulates serotonin and noradrenaline levels $[44,111,114]$. The aforementioned may predict the status of brain excitability during GHB withdrawal, manifested due to disinhibition of glutamate and an increase in dopamine release, which seems to differ in rate and speed from other drugs of abuse. The increased central dopamine levels during the GHB withdrawal phase can persist for 1-2 weeks because of slow elimination of the active metabolite carbon disulphide, leading to delayed psychosis with hallucinations and possible prolonged delirium [165]. In conclusion, the cessation of GHB abuse may result in a rapid withdrawal syndrome based on a complex interaction of different neurobiological mechanisms reached through the stimulation of $\mathrm{GABA}_{B}$ and high-affinity $\mathrm{GHB}$ and $\mathrm{GABA}_{\mathrm{A}}$ receptors. It reveals a level of complexity in regulation and functional alterations well beyond the GABA system, involving several key brain neuromodulators and neurotransmitters, including glutamate, dopamine, serotonin and noradrenaline modifications, as well as others such as neurosteroids and oxytocin. The withdrawal symptoms cannot all be related to a single dominant mechanism or neurological pathway, which implies the need for different medication combinations to proceed with treatment. Detoxification aids with a single drug class, such as benzodiazepines, gabapentin or antipsychotics, will not be sufficient to avoid complications and have been shown to provoke treatment resistance [166, 167]. Physicians should be aware of this complexity, which can be a legitimate explanation for the use of pharmaceutical GHB, in a titration and tapering approach, as a promising detoxification treatment method which could make polypharmacy redundant, especially in the case of dependence on high doses of GHB. In the first weeks after the cessation of abuse, therapists should also consider a potential increase in the impulsive behaviour of GHB-dependent patients, related to a possible persistent high level of dopamine and serotonin disbalance. This behaviour might lead to a rapid relapse in GHB use. Therefore, patients should receive intensive counselling immediately, preferably during detoxification, and should be provided with psychoeducation to decrease relapse rates. It is important, in light of the often unpredictable and severe effects of $\mathrm{GHB}$, to translate the urgency of new insights into treatment tactics and prevention of complications. 
Several limitations of this review are noted. There is limited published research available to reveal the exact neurobiological targets of GHB in humans; therefore, the neurobiological profile dependence and abuse liability has mostly been illustrated from studies in animals. Studies often focused on GABAergic agonist ligands in general and not specifically on GHB. It was difficult to determine whether an exact relationship exists between dependence, withdrawal features and the amount of GHB ingested. Future human studies will be of great help in resolving these important issues.

\section{Disclosure Statement}

The authors have no relevant affiliations or financial involvement with any organization or entity with a financial interest in, or financial conflict with, the subject matter or materials discussed in the paper.

\section{References}

1 Mamelak M: Gamma-hydroxybutyrate: an endogenous regulator of energy metabolism. Neurosci Biobehav Rev 1989;13:187-198.

2 Laborit H: Sodium 4-hydroxybutyrate. Int J Neuropharmacol 1964;3:433-451.

3 Kam P, Yoong F: Gamma-hydroxybutyric acid: an emerging recreational drug. Anaesthesia 1998;53:1195-1198.

4 Boscolo-Berto R, Viel G, Montagnese S, Raduazzo DI, Ferrara SD, Dauvilliers Y: Narcolepsy and effectiveness of gamma-hydroxybutyrate (GHB): a systematic review and metaanalysis of randomized controlled trials. Sleep Med Rev 2012;16:431-443.

5 Addolorato G, Leggio L, Ferrulli A, Caputo F, Gasbarrini A: The therapeutic potential of gamma-hydroxybutyric acid for alcohol dependence: balancing the risks and benefits. A focus on clinical data. Expert Opin Investig Drugs 2009;18:675-686.

6 EMCDDA: Annual Report 2012: The State of the Drugs Problem in Europe. Luxembourg, EU Publications Office, 2012.

7 van Laar MW, Cruts AA, Van Ooyen-Houben MM, Meijer RF, Brunt T, Croes EA: Netherlands National Drug Monitor: NDM Annual Report 2011. Utrecht, Trimbos Institute, 2012.

8 Guerreiro DF, Carmo AL, da Silva JA, Navarro R, Góis C: Club drugs. Review. Acta Med Port 2011:24:739-756.

9 EMCDDA: European Drug Report: Trends and Developments. European Monitoring Centre for Drugs and Drug Addiction. Luxembourg, EU Publications Office, 2013.

10 van Rooij AJ, Schoenmakers TM, van de Mheen D: Nationaal Prevalentie Onderzoek Middelengebruik 2009: Kerncijfers 2009. Rotterdam, Institute for Research in Addiction, 2011.

11 CAM: Risicoschatting gamma-hydroxyboterzuur 2011. Rapport van het CAM; in: Coördinatiepunt Assessment en Monitoring nieuwe Drugs. Bilthoven, CAM, 2011.
12 Bramness J, Haugland S: Abuse of $\gamma$-hydroxybutyrate. Tidsskr Nor Laegeforen 2011; 131:2122-2125

13 Zovsec D, Smith S: Gamma-hydroxybutyrate $(\mathrm{GHB})$ dependence and withdrawal; in Traub SJ (ed): UpToDate Online. 2012. http://www.uptodate.com/contents/gamma-hydroxybutyrate-ghb-dependence-andwithdrawal.

14 Wisselink D, Mol A: GHB hulpvraag in Nederland: belangrijkste ontwikkelingen van de hulpvraag voor GHB problematiek in de verslavingszorg 2007-2012; in: Landelijk Alcohol en Drugs Informatie Systeem (LADIS) 2013. Houten, Stichting IVZ, 2013.

15 Carter LP, Pardi D, Gorsline J, Griffiths R: Illicit gamma-hydroxybutyrate (GHB) and pharmaceutical sodium oxybate (Xyrem): differences in characteristics and misuse. Drug Alcohol Depend 2009;104:1-10.

16 Wood D, Brailsford A, Dargan P: Acute toxicity and withdrawal syndromes related to $\gamma$-hydroxybutyrate $(\mathrm{GHB})$ and its analogues $\gamma$ butyrolactone (GBL) and 1,4-butanediol (1,4BD). Drug Test Anal 2011;3:417-425.

17 Schep LJ, Knudsen K, Slaughter RJ, Vale JA, Megarbane B: The clinical toxicology of gamma-hydroxybutyrate, $\gamma$-butyrolactone and 1,4-butanediol. Clin Toxicol (Phila) 2012;50: 458-470.

18 Zvosec DL, Smith SW, Porrata T, Strobl AQ, Dyer JE: Case series of 226 gamma-hydroxybutyrate-associated deaths: lethal toxicity and trauma. Am J Emerg Med 2011;29:319332.

19 Zvosec D, Smith S, Hall B: Three deaths associated with use of Xyrem. Sleep Med 2009; 10:490-493.

20 Roberts DM, Smith MW, Gopalakrishnan M, Whittaker G, Day RO: Extreme $\gamma$-butyrolactone overdose with severe metabolic acidosis requiring hemodialysis. Ann Emerg Med 2011;58:83-85.

21 Snead O, Gibson KM: $\gamma$-Hydroxybutyric acid. N Engl J Med 2005;352:2721-2732.
22 van Noorden MS, Kamal R, de Jong CA, Vergouwen AC, Zitman F: Gamma-hydroxybutyric acid (GHB) dependence and the GHB withdrawal syndrome: diagnosis and treatment (in Dutch). Ned Tijdschr Geneeskd 2010;154:A1286.

23 van Amsterdam JG, Brunt T, McMaster M, Niesink R: Possible long-term effects of gamma-hydroxybutyric acid (GHB) due to neurotoxicity and overdose. Neurosci Biobehav Rev 2012;36:1217-1227.

24 WHO Expert Committee on Drug Dependence: Critical Review Report. Thirty-Fifth Meeting Gamma-Hydroxybutyric Acid (GHB). Hammamet, World Health Organisation, 2012.

25 Tunnicliff G: Sites of action of gamma-hydroxybutyrate (GHB) - a neuroactive drug with abuse potential. Clin Toxicol 1997;35: 581-590.

26 Wong C, Gibson K, Snead O: From the street to the brain: neurobiology of the recreational drug $\gamma$-hydroxybutyric acid. Trends Pharmacol Sci 2004;25:29-34

27 Andresen H, Aydin BE, Mueller A, IwersenBergmann S: An overview of gamma-hydroxybutyric acid: pharmacodynamics, pharmacokinetics, toxic effects, addiction, analytical methods, and interpretation of results. Drug Test Anal 2011;3:560-568.

28 Le Beau M, Miller M, Levine B: Effect of storage temperature on endogenous GHB levels in urine. Forensic Sci Int 2001;119:161-167.

29 Lyon R, Johnston SM, Watson DG, McGarvie G, Ellis E: Synthesis and catabolism of gamma-hydroxybutyrate in SH-SY5Y human neuroblastoma cells: role of the aldo-keto reductase AKR7A2. J Biol Chem 2007;282: 25986-25992.

30 Kapoor P, Deshmukh R, Kukreja I: GHB acid: a rage or reprieve. J Adv Pharm Technol Res 2013;4:173-178.

Kamal/van Noorden/Franzek/Dijkstra/ Loonen/De Jong 
31 Snead OC 3rd, Furner R, Liu CC: In vivo conversion of gamma-aminobutyric acid and 1,4-butanediol to gamma-hydroxybutyric acid in rat brain. Studies using stable isotopes. Biochem Pharmacol 1989;38:4375-4380.

32 Abanades S, Farre M, Segura M, Pichini S, Barral D, Pacifici R, Pellegrini M, Fonseca F, Langohr K, De La Torre R: Gamma-hydroxybutyrate (GHB) in humans: pharmacodynamics and pharmacokinetics. Ann NY Acad Sci 2006;1074:559-576.

33 Muller C, Viry S, Miehe M, Andriamampandry $C$, Aunis D, Maitre M: Evidence for a $\gamma$ hydroxybutyrate (GHB) uptake by rat brain synaptic vesicles. J Neurochem 2002;80:899904.

34 Gobaille S, Hechler V, Andriamampandry C, Kemmel V, Maitre M: $\gamma$-Hydroxybutyrate modulates synthesis and extracellular concentration of $\gamma$-aminobutyric acid in discrete region in vivo in rat brain regions. J Pharmacol Exp Therap 1999;209:303-309.

35 Palantini P, Tedeschi L, Frison G, Padrini R, Zordan R, Orlando R, Gallimberti L, Gessa GL, Ferrara S: Dose-dependent absorption and elimination of gamma-hydroxybutyric acid in healthy volunteers. Eur J Clin Pharmacol 1993;45:353-356.

36 Zvosec DL, Smith SW, McCutcheon R, Spillane J: Adverse events, including death, associated with the use of 1,4 butanediol. $\mathrm{N}$ Engl J Med 2001;344:87-94

37 Morse BL, Felmlee MA, Morris ME: Gammahydroxybutyrate blood/plasma partitioning: effect of physiologic $\mathrm{pH}$ on transport by monocarboxylate transporters. Drug Metab Dispos 2012;40:64-69.

38 Wang Q, Lu Y, Morris ME: Monocarboxylate transporter (MCT) mediates the transport of gamma-hydroxybutyrate in human kidney HK-2 cells. Pharm Res 2007;24:1067-1078.

39 Morse BL, Vijay N, Morris ME: Gamma-hydroxybutyrate (GHB)-induced respiratory depression: combined receptor-transporter inhibition therapy for treatment in $\mathrm{GHB}$ overdose. Mol Pharmacol 2012;82:226-235.

40 Ottani A, Saltini S, Bartiromo M, Zaffe D, Renzo Botticelli A, Ferrari A, Bertolini A, Genedani S: Effect of gamma-hydroxybutyrate in two rat models of focal cerebral damage. Brain Res 2003;986:181-119.

41 Kemmel V, Klein C, Dembele D, Jost B, Taleb $\mathrm{O}$, Aunis D, Mensah-Nyagan AG, Maitre M: A single acute pharmacological dose of gamma-hydroxybutyrate (GHB) modifies multiple gene expression patterns in rat hippocampus and frontal cortex. Physiol Genomics 2010;41:146-160.

42 Wendt G, Kemmel V, Patte-Mensah C, Uring-Lamert BE, Schmitt MJ, Mensah-Nyagan AG: Gamma-hydroxybutyrate, acting through an anti-apoptotic mechanism, protects native and amyloid-precursor-proteintransfected neuroblastoma cells against oxidative stress-induced death. Neuroscience 2014;263:203-215.
43 Tokumura A, Tanaka T, Yotsumoto T, Tsukatani $\mathrm{H}$ : Identification of $s n-2-\omega$-hydroxycarboxylate-containing phospholipids in a lipid extract from bovine brain. Biochem Biophys Res Commun 1991;177:466-473.

44 Mamelak M: Narcolepsy and depression and the neurobiology of gamma-hydroxybutyrate. Prog Neurobiol 2009;89:193-219.

45 Pedraza C, Garciá FB, Navarro J: Neurotoxic effects induced by gamma-hydroxybutyric acid (GHB) in male rats. Int J Neuropsychopharmacol 2009;12:1165-1177.

46 Sircar R, Basak A, Sircar D, Wu L: Effects of gamma-hydroxybutyric acid on spatial learning and memory in adolescent and adult female rats. Pharmacol Biochem Behav 2010; 96:187-193.

47 Sircar R, Wu L, Reddy K, Sircar D, Basak A: GHB-induced cognitive deficits during adolescence and the role of NMDA receptor. Curr Neuropharmacol 2011;9:240-243.

48 van Nieuwenhuijzen P, Kashem MA, Matsumoto I, Hunt G, McGregor I: A long hangover from party drugs: residual proteomic changes in the hippocampus of rats 8 weeks after gamma-hydroxybutyrate (GHB), 3,4-methylenedioxymethamphetamine (MDMA) or their combination. Neurochem Int 2010;56:871877.

49 Mamelak M, Black J, Montplaisir J, Ristanovic $\mathrm{R}$ : A pilot study on the effects of sodium oxybate on sleep architecture and daytime alertness in narcolepsy. Sleep 2004;27:1327-1334.

50 Lapierre O, Montplaisir J, Lamarre M, Bedard MA: The effect of gamma-hydroxybutyrate on nocturnal and diurnal sleep of normal subjects: further considerations on REM sleeptriggering mechanisms. Sleep 1990;13:24-30.

51 Peterson MJ, Benca RM: Sleep in mood disorders. Psychiatr Clin North Am 2006;29:10091032.

52 Felmlee MA, Roiko SA, Morse B, Morris M: Concentration-effect relationships for the drug of abuse gamma-hydroxybutyric acid. J Pharmacol Exp Ther 2010;333:764-771.

53 Oliveto A, Gentry WB, Pruzinsky R, Gonsai K, Kosten TR, Martell B, Poling J: Behavioral effects of gamma-hydroxybutyrate in humans. Behav Pharmacol 2010;21:332-342.

54 Castelli M: A review of pharmacology of NCS-382, a putative antagonist of $\gamma$-hydroxybutyric acid (GHB) receptor. CNS Drug Reviews 2004;10:243-260.

55 Crunelli V, Emri Z, Leresche N: Unravelling the brain targets of gamma-hydroxybutyric acid. Curr Opin Pharmacol 2006;6:44-52.

56 Bay T, Eghorn LF, Klein AB, Wellendorph P: GHB receptor targets in the CNS: focus on high-affinity binding sites. Biochem Pharmacol 2014;87:220-228.

57 van Nieuwenhuijzen PS, McGregor IS: Sedative and hypothermic effects of gamma-hydroxybutyrate $(\mathrm{GHB})$ in rats alone and in combination with other drugs: assessment using biotelemetry. Drug Alcohol Depend 2009; 103:137-147.
58 Connelly WM, Errington AC, Crunelli V: $\gamma$-Hydroxybutyric acid (GHB) is not an agonist of extrasynaptic $\mathrm{GABA}_{\mathrm{A}}$ receptors. PLoS One 2013;8:e79062.

59 Carai MA, Colombo G, Brunetti G, Melis S, Serra S, Vacca G, Mastinu S, Pistuddi AM, Solinas C, Cignarella G, Gessa GL: Role of GA$\mathrm{BA}_{\mathrm{B}}$ receptors in the sedative/hypnotic effect of gamma-hydroxybutyric acid. Eur J Pharmacol 2001;428:315-321.

60 Gervasi N, Monnier Z, Vincent P, PaupardinTritsch D, Hughes SW, Crunelli V, Leresche $\mathrm{N}$ : Pathway-specific action of gamma-hydroxybutyric acid in sensory thalamus and its relevance to absence seizures. J Neurosci 2003;23:11469-11478

61 Carai M, Lobina C, Maccioni P, Cabras C, Colombo G, Gessa GL: $\gamma$-Aminobutyric acid B $\left(\mathrm{GABA}_{\mathrm{B}}\right)$-receptor mediation of different in vivo effects of $\gamma$-butyrolactone. J Pharmacol Sci 2008;106:199-207.

62 Molnár T, Antal K, Nyitrai G, Emri Z: Gamma-hydroxybutyrate $(\mathrm{GHB})$ induces $\mathrm{GABA}_{\mathrm{B}}$ receptor independent intracellular $\mathrm{Ca}^{2+}$ transients in astrocytes, but has no effect on $\mathrm{GHB}$ or $\mathrm{GABA}_{\mathrm{B}}$ receptors of medium spiny neurons in the nucleus accumbens. Neuroscience 2009;162:268-281.

63 Carter LP, Chen W, Wu H, Mehta A.K, Hernandez RJ, Ticku MK, Coop A, Koek W, France CP: Comparison of the behavioral effects of gamma-hydroxybutyric acid (GHB) and its 4-methyl-substituted analog, gammahydroxyvaleric acid (GHV). Drug Alcohol Depend 2005;78:91-99.

64 Maitre M, Kemmel V, Andriamampandry C, Gobaille S, Aunis D: The role of $\gamma$-hydroxybutyrate in brain function; in Tunnicliff G, Cash, C (eds): Gamma-Hydroxybutyrate: Molecular, Functional and Clinical Aspects. London/New York, Taylor \& Francis, 2002, pp 236-247.

65 Koek W, Flores LR, Carter LP, Lamb RJ, Chen $\mathrm{W}, \mathrm{Wu} \mathrm{H}$ : Discriminative stimulus effects of gamma-hydroxybutyrate (GHB) in pigeons: involvement of diazepam-sensitive and -insensitive $\mathrm{GABA}_{\mathrm{A}}$ receptors and of $\mathrm{GABA}_{B}$ receptors. J Pharmacol Exp Ther 2004;308:904911.

66 Absalom N, Eghornb LF, Villumsenb IS, Karima N, Bayb T, Olsen JV, Knudsend GM, Bräuner-Osborneb H, Frølundb B, Clausenb RP: $\alpha_{4} \beta \delta \mathrm{GABA}_{\mathrm{A}}$ receptors are high-affinity targets for $\gamma$-hydroxybutyric acid (GHB). Neuroscience 2012;109:13404-13409.

67 Nasrallah F, Maher A, Hanrahan J, Balcar V, Rae C: Gamma-hydroxybutyrate and the GABAergic footprint: a metabolomic approach to unpicking the actions of GHB. J Neurochem 2010;115:58-67.

68 Brenneisen R: Pharmacokinetics and excretion of gamma-hydroxybutyrate (GHB) in healthy subjects. J Anal Toxicol 2004;28:625630 . 
69 Abanades S, Farre M, Barral D, Torrens M, Closas N, Langohr K. Pastor A, de la Torre R: Relative abuse liability of gamma-hydroxybutyric acid, flunitrazepam, and ethanol in club drug users. J Clin Psychopharmacol 2007;27: 625-638.

70 Weerts EM, Goodwin AK, Griffiths RR, Brown PR, Froestl W, Jakobs C, Gibson KM: Spontaneous and precipitated withdrawal after chronic intragastric administration of gammahydroxybutyrate (GHB) in baboons. Psychopharmacology (Berl) 2005;179:678-687.

71 Cook H: The abrupt cessation of therapeutically administered sodium oxybate (GHB) does not cause withdrawal symptoms. J Toxicol Clin Toxicol 2003;41:131-135.

72 Addolorato G, Castelli E, Stefanini GF, Casella G, Caputo F, Marsigli L: An open multicentric study evaluating 4-hydroxybutyric acid sodium salt in the medium-term treatment of 179 alcohol dependent subjects. GHB Study Group. Alcohol Alcohol 1996;31:341345.

73 Gallimberti L, Ferri M, Ferrara SD, Fadda F, Gessa G: Gamma-hydroxybutyric acid in the treatment of alcohol dependence: a doubleblind study. Alcohol Clin Exp Res 1992;16: 673-676.

74 Gallimberti L, Spella MR, Soncini CA, Gessa GL: Gamma-hydroxybutyric acid in the treatment of alcohol and heroin dependence. Alcohol 2000;20:257-262.

75 Goodwin A, Kaminski B, Griffiths R, Ator N, Weerts E: Intravenous self-administration of gamma-hydroxybutyrate (GHB) in baboons. Drug Alcohol Depend 2011;114:217-224.

76 Wojtowicz J: Withdrawal from gamma-hydroxybutyrate, 1,4-butanediol and $\gamma$-butyrolactone: a case report and systematic review. CJEM 2008;10:69-74.

77 Dyer J, Roth B, Hyma BA: Gamma-hydroxybutyrate withdrawal syndrome. Ann Emerg Med 2001;37:147-153.

78 Perez E, Chu J, Bania T: Seven days of gammahydroxybutyrate (GHB) use produces severe withdrawal. Ann Emerg Med 2006;48:219220.

79 de Jong C, Kamal R, Dijkstra BA, de Haan HA: Gamma-hydroxybutyrate detoxification by titration and tapering. Eur Addict Res 2012;18:40-45.

80 Craig K, Gomez HF, McManus JL, Bania T: Sever gamma-hydroxybutyrate withdrawal: a case report and literature review. J Emerg Med 2000;18:65-70.

81 Pistis M, Muntoni A, Pillolla G, Perra S, Cignarella G, Melis M, Gessa GL: Gamma-hydroxybutyric acid (GHB) and the mesoaccumbens reward circuit: evidence for $\mathrm{GABA}_{\mathrm{B}}$ receptor-mediated effects. Neuroscience 2005; 131:465-474.

82 Matgorzata F: $\mathrm{GABA}_{\mathrm{B}}$ receptors in drug addiction. Pharmacol Rep 2008;60:755-770.

83 Kalivas PW, Lalumiere RT, Knackstedt L, Shen $\mathrm{H}$ : Glutamate transmission in addiction. Neuropharmacology 2009;56(suppl 1): 169-173.
84 Kalivas P, Volkow N: The neural basis of addiction: a pathology of motivation and choice. Am J Psychiatry 2005;162:1403-1413.

85 Cruz $\mathrm{H}$, Ivanova $\mathrm{T}$, Lunn $\mathrm{M}$, Stoffel $\mathrm{M}$ Slesinger P, Luscher C: Bi-directional effects of $\mathrm{GABA}_{\mathrm{B}}$ receptor agonists on the mesolimbic dopamine system. Nat Neurosci 2004;7: 153-159.

86 Koek W, France C: Cataleptic effects of gamma-hydroxybutyrate $(\mathrm{GHB})$ and baclofen in mice: mediation by $\mathrm{GABA}_{\mathrm{B}}$ receptors, but differential enhancement by N-methyl-D-aspartate (NMDA) receptor antagonists. Psychopharmacology (Berl) 2008;199:191-198.

87 Carter LP, Wu H, Chen W: Novel gammahydroxybutyric acid (GHB) analogs share some, but not all, of the behavioral effects of GHB and $G_{A B A}$ receptor agonists. J Pharmacol Exp Ther 2005;313:1314-1323.

88 Hechler V, Ratomponirina C, Maitre M: Gamma-hydroxybutyrate conversion into GABA induces displacement of $\mathrm{GABA}_{\mathrm{B}}$ binding that is blocked by valproate and ethosuximide. J Pharmacol Exp Ther 1997;281:753760.

89 Mathivet P, Bemasconi R, De Barry J, Marescaux $\mathrm{C}$, Bittiger $\mathrm{H}$ : Binding characteristics of $\gamma$-hydroxybutyric acid as a weak but selective $\mathrm{GABA}_{\mathrm{B}}$ receptor agonist. Euro J Pharmacol 1997;321:67-75.

90 Hensler J, Advani T, Burke TF, Cheng K, Rice $\mathrm{KC}$, Koek W: $\mathrm{GABA}_{\mathrm{B}}$ receptor-positive modulators: brain region-dependent effects. J Pharmacol Exp Ther 2012;340:19-26.

91 Queva C, Bremner-Danielsen M, Edlund A, Ekstrand AJ, Elg S, Erickso S, Johansson T, Lehmann A, Mattsson JP: Effects of GABA agonists on body temperature regulation in $G A B A_{B(1)^{-1}}$ mice. Br J Pharmacol 2003;140: 315-322.

92 Kaupmann K: Specific gamma-hydroxybutyrate- binding sites but loss of pharmacological effects of gamma-hydroxybutyrate in $\mathrm{GABA}_{\mathrm{B} 1}$-deficient mice. Eur J Neurosci 2003; 18:2722-2730.

93 Labouèbe G, Lomazzi M, Cruz HG, Creton C, Luján R, Li M, Yanagawa Y, Obata K, Watanabe M, Wickman K, Boyer SB, Slesinger PA, Lüscher C: RGS2 modulates coupling between $\mathrm{GABA}_{\mathrm{B}}$ receptors and GIRK channels in dopamine neurons of the ventral tegmental area. Nat Neurosci 2007;10:1559-1568.

94 Mark M, Herlitze S: G-protein mediated gating of inward-rectifier $\mathrm{K}^{+}$channels. Eur J Biochem 2000;267:5830-5836.

95 Wickman K, Karschin C, Karschin A, Picciotto MR, Clapham DE: Brain localization and behavioral impact of the G-protein-gated $\mathrm{K}^{+}$ channel subunit GIRK4. Neurosci 2000;20: 5608-5615.

96 Lüscher C, Jan LY, Stoffel M, Malenka R, Nicoll RA: G-protein-coupled inwardly rectifying $\mathrm{K}^{+}$channels (GIRKs) mediate postsynaptic but not presynaptic transmitter actions in hippocampal neurons. Neuron 1997;19: 687-695.
97 Drasbek K, Christensen J, Jensen K: Gamma-hydroxybutyrate - a drug of abuse. Acta Neurol Scand 2006;114:145-156.

98 Hédou G, Chasserot-Golaz S, Kemmel V, Gobaille S, Roussel G, Artault JC, Andriamampandry C, Aunis D, Maitre M: Immunohistochemical studies of the localization of neurons containing the enzyme that synthesizes dopamine, GABA, or gamma-hydroxybutyrate in the rat substantia nigra and striatum. J Comp Neurol 2000;426:549-560.

99 Hechler V, Gobaille S, Maitre M: Selective distribution pattern of $\gamma$-hydroxybutyrate receptors in the rat forebrain and midbrain as revealed by quantitative autoradiography. Brain Res 1992;572:345-348.

100 Ferraro L, Tanganelli S, O'Connor WT, Francesconi W, Loche A, Gessa GL, Antonelli T: $\gamma$-Hydroxybutyrate modulation of glutamate levels in the hippocampus: an in vivo and in vitro study. J Neurochem 2001; 78:929-939.

101 Aizawa M, Ito Y, Fukuda H: Roles of gamma-aminobutyric acid $B\left(\mathrm{GABA}_{\mathrm{B}}\right)$ and gamma-hydroxybutyric acid receptors in hippocampal long-term potentiation and pathogenesis of absence seizures. Biol Pharm Bull 1997;20:1066-1070

102 Banerjee PK, Snead OC 3rd: Presynaptic gamma-hydroxybutyric acid (GHB) and gamma-aminobutyric acid $B\left(G_{A B A}\right)$ receptor-mediated release of GABA and glutamate (GLU) in rat thalamic ventrobasal nucleus (VB): a possible mechanism for the generation of absence-like seizures induced by GHB. J Pharmacol Exp Ther 1995;273: 1534-1543.

103 Loonen AJ: Het beweeglijke Brein. Haarlem, Mension, 2004.

104 Kahn I, Shohamy D: Intrinsic connectivity between the hippocampus, nucleus accumbens, and ventral tegmental area in humans. Hippocampus 2013;23:187-192.

105 Kauer JA, Malenka RC: Synaptic plasticity and addiction. Nature Rev Neurosci 2007; 11:844-858.

106 Carter LP, Koek W, France C: Behavioral analyses of GHB: receptor mechanisms. Pharmacol Ther 2009;121:100-114.

107 Kalivas P: The glutamate homeostasis hypothesis of addiction. Nat Rev Neurosci 2009; 10:561-572.

108 Li Q, Kuhn CM, Wilson WA, Lewis DV: Effects of gamma-hydroxybutyric acid on inhibition and excitation in rat neocortex. Neuroscience 2007;150:82-92.

109 Molnár T, Heja L, Emri Z, Simon A, Nyitrai G, Pal I, Kardos J: Activation of astroglial calcium signaling by endogenous metabolites succinate and gamma-hydroxybutyrate in the nucleus accumbens. Front Neuroenergetics 2011;3:7

110 Wang F, Smith NA, Xu Q, Fujita T, Baba A, Matsuda T, Takano T, Bekar L, Nedergaard M: Astrocytes modulate neural network activity by $\mathrm{Ca}^{2+}$-dependent uptake of extracellular K ${ }^{+}$. Sci Signal 2012;5(218):ra26. 
111 Gobaille S, Schleef C, Hechle V, Viry S, Aunis D, Maitre M: Gamma-hydroxybutyrate increases tryptophan availability and potentiates serotonin turnover in rat brain. Life Sci 2002;70:2101-2112.

112 Hedner T, Lundborg P: Effect of gamma-hydroxybutyric acid on serotonin synthesis, concentration and metabolism in the developing rat brain. J Neural Transm 1983;57: 39-48.

113 Pardridge W, Fierer G: Transport of tryptophan into brain from the circulating albumin-bound pool in rats and in rabbits. J Neurochem 1990;54:971-976.

114 Burman KJ, Ige AO, White JH, Marshall F, Pangalos MN, Emson P, Minson JB, Llewellyn-Smith IJ: $\mathrm{GABA}_{\mathrm{B}}$ receptor subunits, R1 and R2, in brainstem catecholamine and serotonin neurons. Brain Res 2003;970:35-46.

115 Ferré S, Artigas F: Dopamine $\mathrm{D}_{2}$ receptormediated regulation of serotonin extracellular concentration in the dorsal raphe nucleus of freely moving rats. J Neurochem 1993;61: 772-775.

116 Abellan MT, Jolas T, Aghajanian GK, Artigas $\mathrm{F}$ : Dual control of dorsal raphe serotonergic neurons by $\mathrm{GABA}_{B}$ receptors. Electrophysiological and microdialysis studies. Synapse 2000;36:21-34.

117 Szabo S, Gold MS, Goldberger BA, Blier P: Effects of sustained gamma-hydroxybutyrate treatments on spontaneous and evoked firing activity of locus coeruleus norepinephrine neurons. Biol Psychiatry 2004;55: 934-939.

118 Giorgetti M, Bacciottini L, Giovannini MG, Colivicchi MA, Goldfarb J, Blandina P: Local GABAergic modulation of acetylcholine release from the cortex of freely moving rats. Eur J Neurosci 2000;12:1941-1948.

119 Nava F, Carta G, Bortolato M, Gessa GL: $\gamma$-Hydroxybutyric acid and baclofen decrease extracellular acetylcholine levels in the hippocampus via GABA receptors. Eur J Pharmacol 2001;430:261-263.

120 Volpi R, Chiodera P, Caffarra P: Muscarinic cholinergic mediation of the $\mathrm{GH}$ response to gamma-hydroxybutyric acid: neuroendocrine evidence in normal and Parkinsonian subjects. Psychoneuroendocrinology 2000; 25:179-185.

121 Vescovi P, Coiro V: Different control of GH secretion by gamma-amino- and gammahydroxy-butyric acid in 4-year abstinent alcoholics. Drug Alcohol Depend 2001;61: 217-221.

122 Bosch O, Quednow BB, Seifritz E, Wetter TC: Reconsidering GHB: orphan drug or new model antidepressant? J Psychopharmacol 2012;26:618-628.

123 Van Cauter E, Plat L, Scharf MB, Leproult R, Cespedes S, L'Hermite-Balériaux M, Copinschi G: Simultaneous stimulation of slow-wave sleep and growth hormone secretion by gamma-hydroxybutyrate in normal young Men. J Clin Invest 1997;100:745-753.
124 Camacho A, Matthews SC, Murray B, Dimsdale JE: Use of GHB compounds among college students. Am J Drug Alcohol Abuse 2005;31:601-607.

125 Mellon S, Griffen L: Neurosteroids: biochemistry and clinical significance. Trends Endocrinol Metab 2002;13:35-43.

126 Koek W, Carter LP, Lamb RJ, Chen W, Wu H, Coop A, France C: Discriminative stimulus effects of gamma-hydroxybutyrate (GHB) in rats discriminating GHB from baclofen and diazepam. J Pharmacol Exp Ther 2005;314:170-179.

127 Barbaccia ML, Carai MA, Colombo G, Lobina C, Purdy RH, Gessa G: Endogenous gamma-aminobutyric acid $\left(\mathrm{GABA}_{\mathrm{A}}\right)$ receptor active neurosteroids and the sedative/ hypnotic action of gamma-hydroxybutyric acid (GHB): a study in GHB-S (sensitive) and GHB-R (resistant) rat lines. Neuropharmacology 2005;49:48-58.

128 Barbaccia ML, Colombo G, Affricano D, Carai MA, Vacca G, Melis S, Purdy RH, Gessa GL: $\mathrm{GABA}_{\mathrm{B}}$ receptor-mediated increase of neurosteroids by $\gamma$-hydroxybutyric acid. Neuropharmacology 2002;42:782-791.

129 Greiner C, Röhl JE, Gorji A, Wassmann H, Speckmann EJ: Different actions of gammahydroxybutyrate: a critical outlook. Neurol Res 2003;25:25:759-763.

130 Hechler V, Gobaille S, Bourguignon JJ, Maitre M: Extracellular events induced by gamma-hydroxybutyrate in striatum: a microdialysis study. J Neurochem 1991;56:938-944.

131 Mahler S, Smith RJ, Moorman DE, Sartor GC, Aston-Jones G: Multiple roles for orexin/hypocretinin addiction. Prog Brain Res 2012;198:79-121.

132 Bayard S, Dauvilliers YA: Reward-based behaviors and emotional processing in human with narcolepsy-cataplexy. Front Behav Neurosci 2013;7:50

133 Boutrel B, Steiner N, Halfon O: The hypocretins and the reward function: what have we learned so far? Front Behav Neurosci 2013;7:59.

134 Bell J, Collins R: Gamma-butyrolactone (GBL) dependence and withdrawal. Addiction 2011;106:442-447.

135 McDonough M, Kennedy N, Glasper A, Bearn J: Clinical features and management of gamma-hydroxybutyrate (GHB) withdrawal: a review. Drug Alcohol Depend 2004;75:3-9.

136 Maitre M, Andriamampandry C, Kemmel V, Schmidt C, Hodé Y, Hechler V, Gobaille S: Gamma-hydroxybutyric acid as a signaling molecule in brain. Alcohol 2000;20:277283.

137 Schmidt-Mutter C, Muller C, Zwiller J: Gamma-hydroxybutyrate and cocaine administration increases mRNA expression of dopamine $D_{1}$ and $D_{2}$ receptors in rat brain. Neuropsychopharmacology $1999 ; 21: 662-$ 669.
138 van Noorden MS, van Dongen LC, Zitman FG, Vergouwen TA: Gamma-hydroxybutyrate withdrawal syndrome: dangerous but not well-known. Gen Hosp Psychiatry 2009; 31:394-396

139 Wong CG, Chan KF, Gibson KM, Snead O: Gamma-hydroxybutyric acid: neurobiology and toxicology of a recreational drug. Toxicol Rev 2004;23:3-20.

140 Volkow ND, Wang, GJ, Fowler JS, Logan J, Gatley SJ, Hitzemann R, Chen AD, Dewey SL, Pappas N: Decreased striatal dopaminergic responsiveness in detoxified cocaine-dependent subjects. Nature 1997;386:830-833.

141 Goldstein RZ, Volkow ND: Drug addiction and its underlying neurobiological basis: neuroimaging evidence for the involvement of the frontal cortex. Am J Psychiatry 2002; 159:1642-1652.

142 Asensio S, Romero MJ, Romero FJ, Wong C, Alia-Klein N, Tomasi D, Wang G, Telang F, Volkow ND, Goldstein RZ: Striatal dopamine $\mathrm{D}_{2}$ receptor availability predicts the thalamic and medial prefrontal responses to reward in cocaine abusers three years later. Synapse 2010;64:397-402.

143 Miotto K, Roth B: GHB Withdrawal Syndrome. Austin, Texas Commission on Alcohol and Drug Abuse (TCADA), 2001.

144 Karreman M, Moghaddam B: The prefrontal cortex regulates the basal release of dopamine in the limbic striatum: an effect mediated by ventral tegmental area. J Neurochem 1996;66:589-598.

145 Vilke GM, Bozeman WP, Dawes DM, Demers G, Wilson MP: Excited delirium syndrome (ExDS): treatment options and considerations. J Forensic Leg Med 2012;19: 117-121.

146 Stijnenbosch PJ, Zuketto C, Beijaert PJ, Maat A: GHB withdrawal delirium (in Dutch). Ned Tijdschr Geneeskd 2010;154:A1086.

147 Supady A, Schwab T, Busch HJ: 'Liquid ecstasy': $\gamma$-butyrolactone withdrawal delirium with rhabdomyolysis and dialysis dependent renal failure. Dtsch Med Wochenschr 2009; 134:935-937.

148 Bhattacharya I, Watson F, Bruce M: A case of $\gamma$-butyrolactone associated with severe withdrawal delirium and acute renal failure. Eur Addict Res 2011;17:169-171.

149 Tarabar AF, Nelson LS: The gamma-hydroxybutyrate withdrawal syndrome. Toxicol Rev 2004;23:45-49.

150 Eiden C, Capdevielle D, Deddouche C, Boulenger JP, Blayac JP, Peyrière H: Neuroleptic malignant syndrome-like reaction precipitated by antipsychotics in a patient with $\gamma$-butyrolactone withdrawal. J Addict Med 2011;5:302-303.

151 Ghio L, Cervetti A, Respino M, Belvederi Murri M, Amore M: Management and treatment of $\gamma$-butyrolactone withdrawal syndrome: a case report and review. J Psychiatr Pract 2014;20:294-300. 
152 Nardou R, Yamamoto S, Bhar. A, Burnashev N, Ben-Ari Y, Khalilov I: Phenobarbital but not diazepam reduces AMPA/kainite receptor mediated currents and exerts opposite actions on initial seizures in the neonatal rat hippocampus. Front Cell Neurosci 2011;5: 16.

153 Crunelli V, Emri Z, Leresche N: Unravelling the brain targets of gamma-hydroxybutyric acid. Curr Opin Pharmacol 2006;6:44-52.

154 LeTourneau J, Hagg D, Smith S: Baclofen and gamma-hydroxybutyrate withdrawal. Neurocrit Care 2008;8:430-433.

155 Kamal R, van Noorden MS, Dijkstra BA, Mauritz R, de Jong C: A case series of pharmaceutical gamma-hydroxybutyrate in 3 patients with severe benzodiazepine-resistant gamma-hydroxybutyrate withdrawal in the hospital. Psychosomatics 2015;56:404409.

156 Dijkstra B, De Weert-van Oene GH, Verbrugge CA, De Jong C: GHB Detoxificatie met farmaceutische GHB. Eindrapportage van de monitoring van DeTiTap ${ }^{\circledR}$ in de Nederlandse verslavingszorg. Nijmegen, Nijmegen Institute for Scientist-Practitioners in Addiction, 2013.
157 Oades R: Dopamine may be 'hyper' with respect to noradrenaline metabolism, but 'hypo' with respect to serotonin metabolism in children with attention-deficit hyperactivity disorder. Behav Brain Res 2002;130: 97-102.

158 Winstanley C, Theobald DE, Dalley JW, Robbins T: Interactions between serotonin and dopamine in the control of impulsive choice in rats: therapeutic implications for impulse control disorders. Neuropsychopharmacology 2005;30:669-682.

159 Steeves T, Miyasaki J, Zurowski M, Lang AE, Pellecchia G, Van Eimeren T, Rusjan P, Houle S, Strafella AP: Increased striatal dopamine release in parkinsonian patients with pathological gambling: a $\left[{ }^{11} \mathrm{C}\right]$ raclopride PET study. Brain Res 2009;132:13761385.

160 Winstanley C, Cocker PJ, Rogers R: Dopamine modulates reward expectancy during performance of a slot machine task in rats: evidence for a 'near-miss' effect. Neuropsychopharmacology 2011;36:913-925.
161 O’Sullivan S, Evans AH, Lees AJ: Dopamine dysregulation syndrome: an overview of its epidemiology, mechanisms and management. CNS Drugs 2009;23:157-170.

162 Dalley J, Roiser J: Dopamine, serotonin and impulsivity. Neuroscience 2012;215:42-58.

163 Chamberlain SR, Sahakian BJ: The neuropsychiatry of impulsivity. Curr Opin Psychiatry 2007;20:255-261.

164 Boy F, Evans CJ, Edden RA, Lawrence AD, Singh KD, Husain M, Sumner P: Dorsolateral prefrontal gamma-aminobutyric acid in men predicts individual differences in rash impulsivity. Biol Psychiatry 2011;70:866872.

165 Cagnin A, Pompanin S, Manfioli V, Briani C, Zambon A, Saladini M, Dam M: Gammahydroxybutyric acid-induced psychosis and seizures. Epilepsy Behav 2011;21:203-205.

166 Bennett W, Wilson LG, Roy-Byrne P: Gamma-hydroxybutyric acid (GHB) withdrawal: a case report. J Psychoactive Drugs 2007;39: 293-296.

167 Rosenberg M, Deerfield LJ, Baruch E: Two cases of severe gamma-hydroxybutyrate withdrawal delirium on a psychiatric unit: recommendations for management. Am J Drug Alcohol Abuse 2003;29:487-496. 